\title{
Low-Noise Operating Mode for Propeller-Driven Electric Airplanes
}

\author{
Jeffrey J. Berton* \\ NASA Glenn Research Center, Cleveland, Ohio 44135 \\ and \\ Douglas M. Nark ${ }^{\dagger}$ \\ NASA Langley Research Center, Hampton, Virginia 23681
}

\begin{abstract}
Mechanical shaft power and shaft speed of reciprocating internal combustion engines are closely coupled. Maximum rated shaft power is typically produced at or near peak shaft speed. If a general aviation airplane equipped with a reciprocating engine and a variable-pitch propeller attempts a low-noise takeoff by reducing propeller tip speed, propeller power and thrust are reduced. Such takeoffs are not tolerated due to punishing performance effects, such as increased field lengths and poor climb rates. Certain electric motors, however, are able to deliver maximum shaft power over a wide range of shaft speed. Electric or hybrid-electric propeller-driven airplanes should be able to exploit this behavior. At low shaft speeds, high shaft power levels and high blade pitch angles could be combined to recover much of the thrust that would otherwise be lost. This could enable a low-noise operating mode for propellers normally designed for performance rather than for noise. The subject of this paper is an analytical investigation into low-noise takeoffs and steady overflights of a notional general aviation airplane equipped with a propeller driven by an electric motor.
\end{abstract}
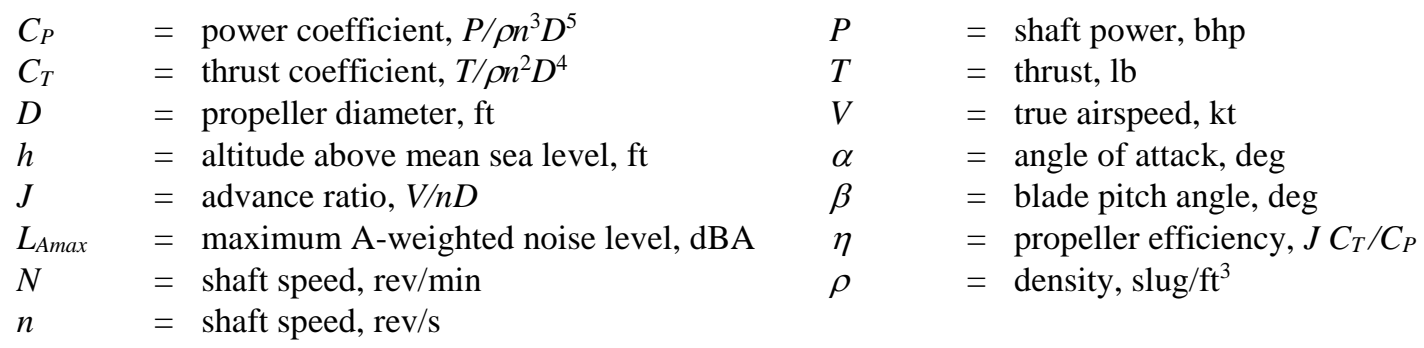

\section{Introduction}

MALL electric airplanes are potentially disruptive innovations enabled by rapidly-emerging battery and electronic technologies. Better airplanes are promised by clever, synergistic integration of electric propulsion with airframe structures, aerodynamics and control systems. Transformative new airplane architectures may be possible by exploiting "distributed electric propulsion." Rather than one or two large engines with propellers, many small propellers driven by tiny electric motors can be distributed across the vehicle. NASA's experimental X-57 Maxwell, for example (Figure 1), is planned to have fourteen propellers. Propellers mounted along the span of a wing can increase lift via enhanced circulation, allowing the wing to shrink in size and weight. Propellers located on wingtips can recover lost vortex energy. Several other structural, aerodynamic and control benefits are possible by distributing propellers around the vehicle.

\footnotetext{
*Aerospace Engineer, Propulsion Systems Analysis Branch, MS 5-11, senior member AIAA.

${ }^{\dagger}$ Senior Research Scientist, Research Directorate, Structural Acoustics Branch, MS 461, AIAA Associate Fellow.
} 
The benefits of unfettered design freedom seem to be there for the taking, if only we have the will and the vision to seize them. After all, it can be argued that the first automobiles were not simply mechanical versions of the horses they replaced, despite several suggestions and patents of that era. In 1878, a mechanical "power horse" ([2], Figure 2) was designed to "mechanically imitate the step of a horse." But automobiles do not resemble horses, and airplanes and ships seem to fare better as rigid structures equipped with propellers rather than as flapping ornithopters or mechanical fish. So it would seem that, given a transformative technology, transformative architectures should follow.

But if we are borrowing from history, there are many examples of old architectures that have persisted through and beyond an innovation. Might there be a place for conventionallooking electric general aviation airplanes having just a single motor and propeller, perhaps coexisting with more exotic electric airplanes with multiple propellers?

To illustrate, Cirrus Aircraft's four-place SR20 (Figure 3) is representative of a modern general aviation airplane equipped with a single engine and a single propeller. The cost of the SR20's propeller, spinner and associated mounting and overhaul kits exceeds US $\$ 22,000$ [3]. The blade pitch-change governor device, ice protection and other systems can add thousands more. For the most part, these costs would recur with each propeller added. And one large electric motor and propeller should be more efficient (in isolation, at least) than many smaller electric motors and propellers combined to make the same thrust. And for an airplane with many smaller propellers, considerations for bird strikes may lead to thick blade sections with poorer aerodynamics. Further, propeller hub and bearing designs with effective lubrication and blade retention ability may be more difficult to duplicate at smaller scales. Cost of propeller overhauls, repairs and consumable parts should increase directly with the number of propellers. Proponents of distributed electric propulsion argue that synergistic improvements elsewhere across the entire airplane should offset these issues and costs. But if improvements in other areas fail to develop, general aviation aircraft with distributed electric propulsion might be priced out of reach of many buyers.

Thus, the focus of this paper is the study of a single-engine, single-propeller, notional electric general aviation airplane. A Cirrus Aircraft SR20 is "analytically electrified" by substituting its Continental Motors, Inc. IO-360-ES reciprocating engine with a single electric motor creating the same maximum mechanical shaft power at sea level. The hypothetical SR20 electric variant in this study is a simple thought experiment. It is not meant to be an endorsement of such a concept, nor is it intended to detract from the development of any future foray into the electric aircraft market by Cirrus Aircraft. The SR20 electric variant is assumed to have the same maximum takeoff gross weight, aerodynamics, sea level takeoff power, and propeller as the actual SR20. The power source for the electric motor and other electrical systems are unnecessary to define for the purpose of this study and are therefore unspecified (although further development in electric technologies may be necessary if it is to have performance similar to a conventional SR20).

Induction and synchronous electric motors, furnished with appropriate power management equipment and speed controllers, are able to vary shaft speed by adjusting the frequency of the power supplied to the motor. In application, shaft torque can be made constant from rest to the shaft speed defined by the so-called rated frequency. But above the rated frequency, the motor is in the field flux control, or constant voltage regime. Here, torque diminishes with shaft

2 of 11

American Institute of Aeronautics and Astronautics 
speed, and shaft output power remains relatively constant. The constant-power operating regime is the focus of this study. In practice, this behavior can be loosely described as an "electronic gearbox" that allows peak rated shaft power output to occur at a selectable range of shaft speeds.

This behavior is very much unlike a reciprocating internal combustion engine, where 1) shaft power and engine speed are closely coupled, 2) peak shaft power occurs at or near peak engine speed, 3) shaft power falls precipitously below peak engine speed, and 4) a mechanical gearbox with variable gear ratio would be necessary to deliver peak shaft power at an arbitrary shaft speed. It should be noted before moving on that a mechanical gearbox with variable gear ratio is another means to accomplish high- and low-speed operation of a propeller. However, shifting gears (quite literally, on-the-fly!) has not become popular, despite at least one serious investigation unrelated to noise in 1941 [4]. A continuously-variable transmission could manage the job also, provided it could be made lightweight, reliable, safe, and able to handle internal forces well enough. But gearboxes notwithstanding, if an ordinary general aviation airplane equipped with a reciprocating engine attempts a low-noise takeoff by reducing propeller tip speed, propeller power will also be reduced. Such takeoffs are not tolerated due to punishing performance effects, such as decreased acceleration, increased field lengths and poor climb rates.

But the constant-power behavior of an electric motor can be exploited by a variable-pitch propeller. Electric or hybrid-electric general aviation airplanes equipped with electric motors and variable-pitch propellers should be able to operate at maximum shaft power across a wide range of shaft speed. At low shaft speeds, high shaft power levels and high blade pitch angles could be combined to recover much of the thrust that would otherwise be lost. This could enable a low-noise operating mode for propellers normally designed for performance rather than for noise.

And of course, the noise of the reciprocating engine is absent in an electric airplane. Even with effective muffling and mounting systems, the noise, vibration and harshness are difficult to suppress, and they are leading sources of pilot fatigue. Reciprocating engines also contribute to noise levels propagating to observers on the ground, and in some applications, they can be louder than propeller noise.

This study is not related to the design of a low-noise, electrically-driven propeller. Indeed, that is an interesting design and optimization problem of larger scope (e.g., [5]). Designing a propeller for low noise is usually in conflict with generating thrust efficiently. The six-blade, wide-chord, low-speed propeller designed for the Lockheed prototype QT-2PC quiet observation plane is an example of this conflict. Instead, this study is intended to estimate the noise benefits of operating propellers already designed for thrust and efficiency in the low-noise mode described. A pilot could switch between low-noise and high-performance operating modes as necessary and when practicable. Lownoise takeoffs at airports where noise is considered a problem may be possible. The low-noise mode could also be used during en route flight. Low-noise, steady flight over areas requiring quiet operation may be possible. A low-noise operating mode could be helpful over residential areas or at night when demands for quiet are more common.

Simulated low-noise takeoffs and overflights of an electric general aviation airplane are investigated. A noise certification takeoff test of a notional Cirrus SR20 electric variant is analytically modeled using NASA tools. The noise regulations defined by ICAO's Annex 16 for light, propeller-driven airplanes (i.e., Chapter 10 of [6]) are observed. Noise propagated to observers on the ground for steady, level, en route cruise overflights at various altitudes are predicted also. Comparisons to the conventional SR20 powered by its IO-360-ES reciprocating engine are made. This study is a more in-depth continuation of the concept, conceived by the lead author in the late 1990s, briefly analyzed, and described in a 2003 report [7].

\section{Analysis}

\section{A. Motors}

To make a fair noise comparison, our notional electric motor is proposed to create the same rated mechanical shaft power as the SR20's original stock reciprocating engine. Normally rated at 210bhp at 2800rpm at sea level on a standard day, the Continental Motors, Inc. IO-360-ES has been derated by Cirrus Aircraft to 200bhp at 2700rpm [8]. The electric motor therefore is assumed to produce a maximum 200bhp $(150 \mathrm{~kW})$, but with selectable shaft speeds ranging from 2000rpm to 2700rpm. Having identical power ratings, the electric SR20 variant would have similar takeoff field distances and initial climb rates as the actual SR20.

Though maximum shaft power may be assumed constant throughout the selectable range of shaft speeds, electric motor efficiency would of course vary. In practice, at least without any noise considerations, the shaft speed that maximizes the combined efficiency of the electric motor, propeller system, and the entire airplane for a given flight condition and thrust requirement would be preferred. This optimization should of course be mindful of motor and propeller operating limits, and should be an interesting engine control system challenge [9]. A full-authority, digital

3 of 11

American Institute of Aeronautics and Astronautics 
engine control system and a clever propeller hub mechanism might be developed to schedule propeller speed and blade pitch angle with motor system characteristics and airplane thrust requirements.

Unlike airbreathing reciprocating engines, electric motors are insensitive to changes in altitude. And provided they are effectively cooled, electric motors are also insensitive to changes in ambient temperature. Using engine performance charts from the IO-360 series engine manual [10], mechanical shaft power can be shown as a function of shaft speed and altitude for standard day conditions (Figure 4). Wide-open throttle performance at maximum manifold air pressure is of particular interest in a takeoff analysis. By design, the shaft power of our electric motor is identical to the IO-360-ES at sea level and at maximum shaft speed. But at all other conditions, the electric motor enjoys a considerable mechanical shaft power advantage over the reciprocating engine.

In cruising flight, part-power operation of the IO-360-ES is accomplished by adjusting engine throttle and leaning the fuel mixture. For the electric motor, part-power would be achieved by electronic power conditioning equipment.

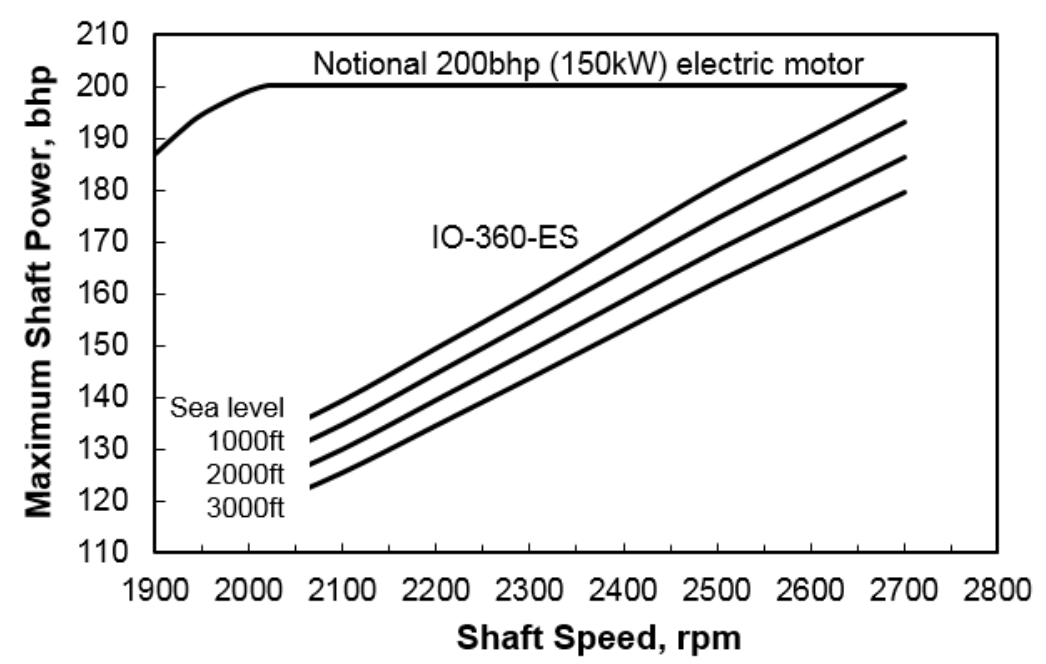

Figure 4. Continental Motors IO-360-ES maximum power performance relative to notional 200bhp electric motor.

\section{B. Propeller Similitude}

Dimensional analysis is often used to gain insight into the behavior of physical systems. Consider a propeller blade of fixed geometry: i.e., the blade airfoil stack is fixed. It is reasonable to assume that the thrust $(T)$ and power $(P)$ acting on the blades are functions of physical properties such as propeller diameter $(D)$, its rotational speed $(n)$, forward airspeed $(V)$, as well as the ambient fluid density $(\rho)$, bulk elastic modulus, viscosity, and pressure. One example of a propeller dimensional analysis using these dependencies can be found in [11]. Other dimensional analyses of propellers have included additional (or fewer) dependencies, but these are enough to determine a reasonable set of dimensionless groupings. For convenience, the dimensionless advance ratio $J$ is defined as $V / n D$ : a measure of the rate a propeller advances, or corkscrews through the air. Following from the dimensional analysis, a thrust coefficient $C_{T}$ and a power coefficient $C_{P}$ can be defined as $T / \rho n^{2} D^{4}$ and $P / \rho n^{3} D^{5}$, respectively. They are (primarily) functions of $J$, tip Mach number, and Reynolds number. If variable-pitch propellers are allowed, $C_{T}$ and $C_{P}$ are additionally functions of blade pitch angle $\beta$. The propeller efficiency $\eta$ can be shown to be $J C_{T} / C_{P}$.

If Reynolds effects are small, scalable propeller performance "maps" of $C_{T}$ and $C_{P}$ can be constructed for geometrically similar propellers (i.e., ones in which the airfoil stack definitions and blade counts are identical, but may differ in scale). If geometric and aerodynamic similitude is to be trusted at all, a propeller may operate as easily at any point on its propeller map as any other, regardless of shaft speed, provided it does not enter prohibited areas of stall, maximum airspeed, maximum shaft speed, or where excessive compressibility rears its head. A propeller need not be limited to operation at constant shaft speed: the norm of so-called "constant-speed propellers" common in general aviation.

To the point, operating lines plotted on performance maps become dissimilar when a propeller is driven by different means. For example, as the IO-360-ES shaft speed falls, so does shaft power. But our notional electric motor can maintain maximum power across a wide range of shaft speed. As its shaft speed falls, blade pitch must increase to absorb the power, and operating lines diverge.

The SR20's optional propeller is a 74-inch Hartzell three-blade PHC-J3YF-1MF/F7392-1 model. Sample operating lines for the two motors are plotted on the Hartzell performance map in Figure 5. $C_{T}, C_{P}$ and $\eta$ are plotted as functions of advance ratio $J$ and for blade pitch angles shown as fractions of a reference blade pitch angle.

4 of 11

American Institute of Aeronautics and Astronautics 
The operating lines shown are constructed for constant thrust, but at different shaft speeds. The IO-360-ES turns at a rate of 2500rpm, while the electric motor operates in a low-noise mode at 2100rpm. Advance ratio increases as airspeed increases. Other operating lines can be constructed and located elsewhere, but this choice illustrates as well as any how the operating lines differ when shaft speed and power are allowed to vary. All points along the operating lines generate identical thrust, albeit at different efficiencies.

Note that absorbing large amounts of power as shaft speed falls is not perpetually sustainable. If shaft speed continues to fall and blade pitch increases to compensate, eventually the propeller blades will stall. This propeller - if we expect it to absorb 200bhp at sea level static - will begin to stall at about 2000rpm. That condition lies off the charts shown in Figure 5.

In the case of an electric airplane, the hydraulic pitch-change mechanism of a constant-speed propeller would be replaced by an electrically-operated mechanism and a digital engine controller. Though they are clever innovations, constant-speed propellers can be inferior to true variable-pitch propellers in some operating conditions. Maximum shaft speed is preferred to create thrust with a given amount of power at static or at low airspeeds, but at higher airspeeds this preference can change. Points A and B in Figure 5, to show just one example, represent part-power cruising conditions where thrust, airspeed and altitude all are identical. The blade pitch angles for points A and B are forty and fifty percent of the reference pitch, respectively. The shaft speed at point $\mathrm{A}$ is $2500 \mathrm{rpm}$ : a typical partpower cruise setting for the SR20 and its constant-speed propeller. But even though point $\mathrm{A}$ has the highest efficiency available for its blade pitch angle, point B enjoys a higher efficiency (more than one point) at a lower shaft speed and higher blade pitch angle. A constant-speed propeller set to operate at 2500rpm would not be able to exploit this situation as flight conditions change as well as a genuine variable-pitch propeller. Further, lower tip speeds are preferred to delay the onset of compressibility.

\section{Noise}

NASA's Aircraft Noise Prediction Program (ANOPP $[12,13]$ ) incorporates a Propeller Analysis System (PAS $[14,15])$ : a predictive capability for aerodynamics, performance, and noise of propellers. Classical aerodynamic theory
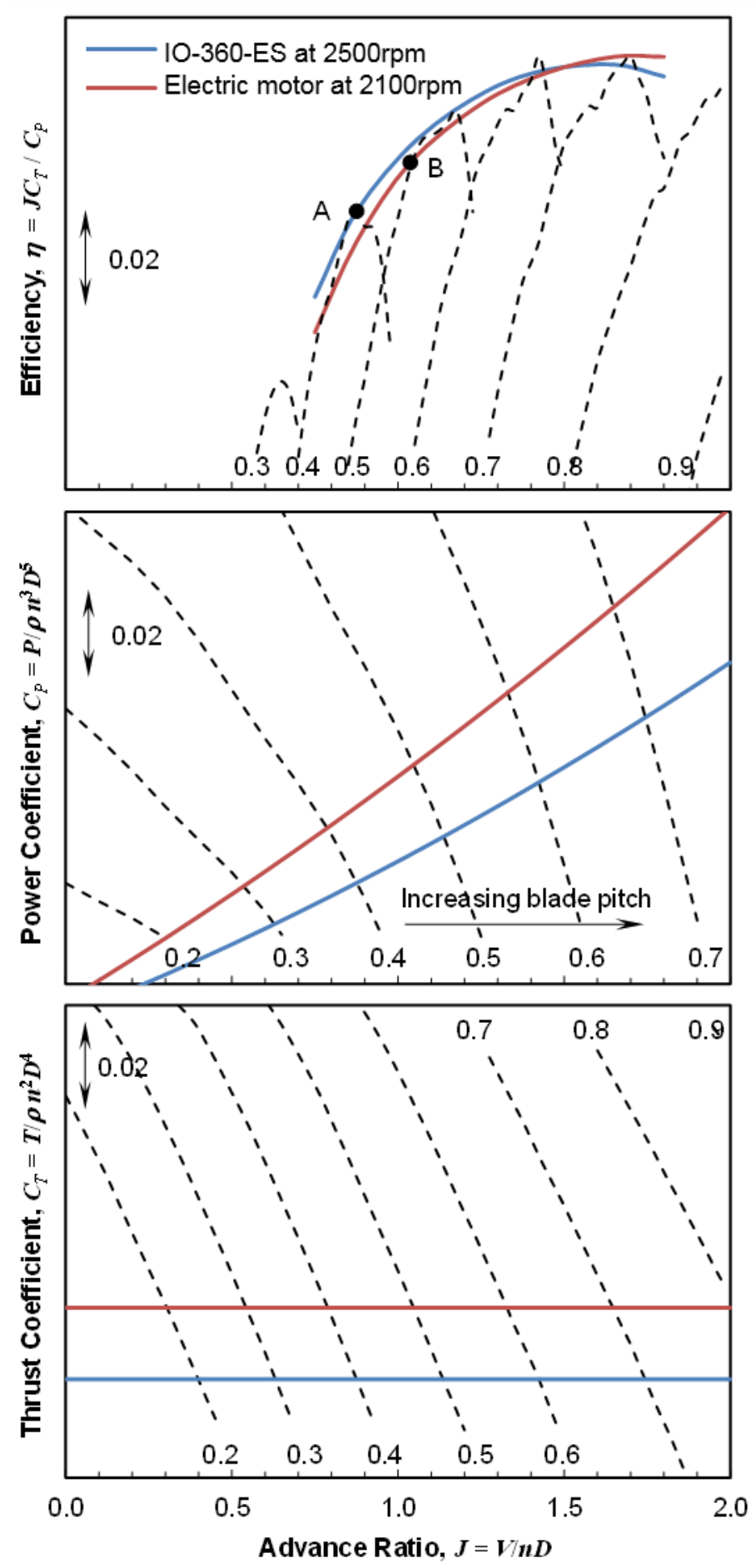

Figure 5. Propeller performance maps with IO-360-ES and notional electric motor operating lines.

5 of 11

American Institute of Aeronautics and Astronautics 
is used to find the surface pressures and frictional stresses on the blade surfaces. Propeller airfoil sections are defined by the user and blade surface coordinates are generated by a conformal mapping process using a Joukowski transform. Potential flow around the blade sections is computed by Theodorsen's method, using the Kutta condition to fix circulation. Blade boundary layers are computed with the Holstein-Bohlen method in the laminar region and with the Truckenbrodt method in the turbulent region.

The acoustic prediction methods used in this study are based on the Ffowcs Williams-Hawkings (FW-H) equation [16]. The FW-H equation is a rearrangement of the exact continuity and Navier-Stokes equations into a wave equation for density with a nonlinear forcing term. Through the application of generalized functions and a Green's function technique, the solution to the equation can be reduced to a surface integral and a volume integral, though the solution is often well-approximated by the surface integral alone. The volume integral includes physical effects such as refraction and nonlinear steepening. When these effects are small, the FW-H surface can coincide with the solid body generating the unsteady flow. This is often referred to as an impermeable data surface. When effects such as refraction are important, the FW-H surface can be pushed out into the flow to encompass important flow gradients. In this case, the data surface is referred to as being permeable (also, penetrable or porous). Hence, the time history of density, which is directly related to the pressure in the far field, can be obtained at locations far from the body from a surface integral that is either close to or on the actual body. For permeable surfaces located off the body, the time histories of all the flow variables are needed, but no spatial derivatives are explicitly required. For surfaces coinciding with the body, only the pressure time history is needed.

In this investigation, propeller source noise is calculated using the PAS subsonic propeller noise module, which implements Farassat's retarded-time "Formulation 1A" of the FW-H equation. All acoustic predictions are based on impermeable data surfaces and the propeller blades are assumed rigid, with shapes taken to be identical at all speeds. The surface pressure loading is taken to be periodic; that is, changing as a function of azimuthal angle and repeating on a once-per-revolution basis. Specifically, time-dependent surface pressure loading values for one full rotor revolution are extracted from the aerodynamic predictions and are used as input.

As the source is analytically flown through the air, its acoustic signature changes. From the viewpoint of a stationary observer, distance and emission angles vary as the source first approaches and then recedes. Doppler shift and convective amplification alter levels and pitch observed on the ground. As the emissions propagate, they are influenced by spherical spreading, atmospheric absorption [17], and ground effects [18, 19]. These effects are modeled by ANOPP/PAS. An analytical simulation of a Chapter 10 noise certification test is performed for the SR20 and its electric variant taking off with various shaft speeds.

\section{Results and Discussion}

\section{A. Takeoff Performance}

Takeoff trajectories for the stock SR20 and its electric variant are analytically simulated using the Flight Optimization System software [20]. Thrust levels are computed using Hartzell propeller performance maps and maximum shaft power levels of the two motors (shown in Figure 4). Aerodynamics for the SR20 are estimated using a handbook method [21] and are adjusted slightly to match flight performance data reported in the SR20 Pilot's Operating Handbook [8]. Whether equipped with the stock IO-360-ES or the electric motor, the SR20 takeoff weight and aerodynamics are assumed to be identical. Only shaft power and thrust levels differ. A maximum propeller thrust comparison of the two motors at sea level is shown in Figure 6. In the Figure, maximum thrust is computed for airspeeds ranging from static to $150 \mathrm{kts}$ at sea level. Or at treetop level, with any luck. Thrust recovered by the electricmotor-driven propeller at low shaft speeds can be clearly seen in the Figure. The electric variant is able to exploit the high shaft power available by increasing blade pitch angles as shaft speed falls. Thrust recovery by the electric motor is particularly good at higher airspeeds, where very little thrust is lost as shaft speed dwindles. The thrust advantage of the electric variant is even more dramatic in conditions where maximum shaft power of the IO-360-ES deteriorates, such as at altitudes above sea level or in hotter ambient air.

Section 10.5.2 of noise certification procedures [6] requires engine takeoff "power" to be selected and maintained throughout the noise test, from brake release to beyond the noise measurement location. But takeoff "power" may seem a bit hazily defined when discussing airplanes with electrical power, especially when (as in this study) maximum mechanical shaft power occurs over a selectable range of shaft speeds. In the case of light aircraft powered by reciprocating engines or small turbine engines, the intent of the regulation is to require airplanes to operate at their maximum takeoff-rated engine power as defined in the Airplane Flight Manual or Pilot's Operating Handbook. The SR20 handbook, for example, lists just one engine takeoff power rating for the stock IO-360-ES: full rich injection mixture and wide-open throttle at 2700rpm, producing 200bhp at sea level.

6 of 11

American Institute of Aeronautics and Astronautics 

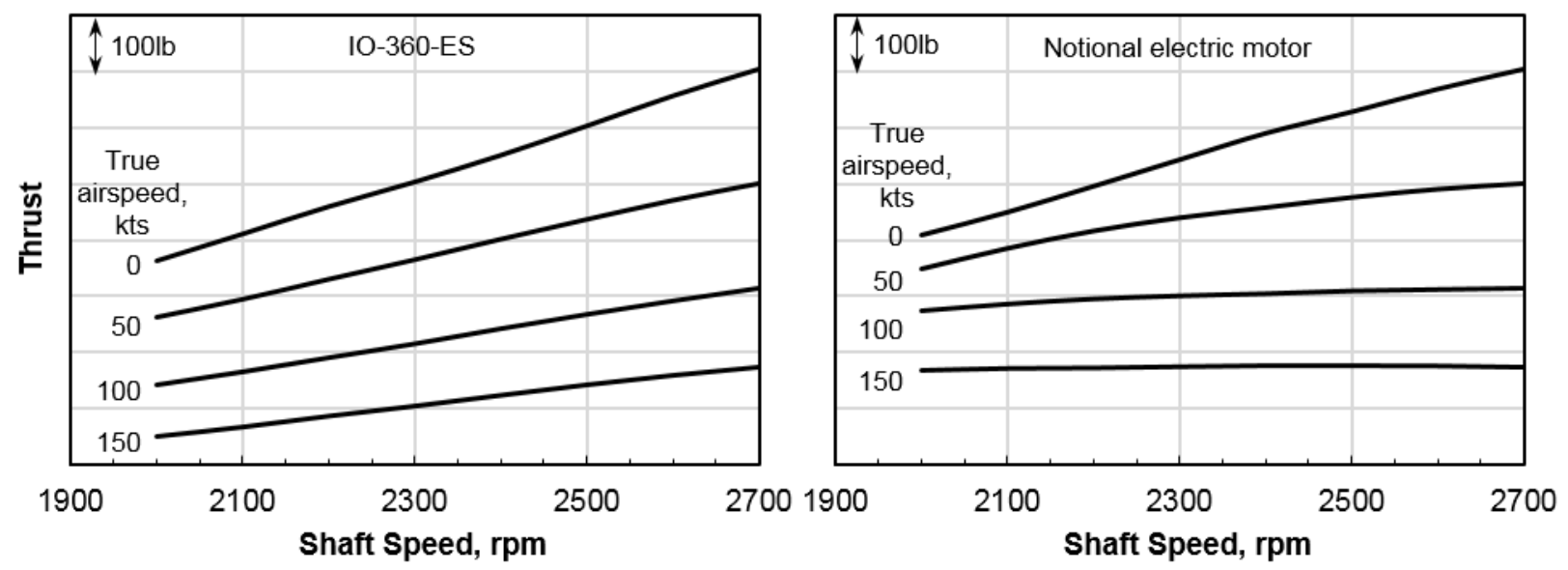

Figure 6. Maximum sea level propeller thrust; with IO-360-ES (left), vs. notional electric motor (right).

It is easy to see why. In Figure 7 (left), takeoff reference trajectories are shown for the SR20 with the stock IO360 -ES. If noise certification procedures could be ignored by reducing engine speed below the 2700rpm maximum, takeoff field lengths and climb rates would suffer dramatically and would not be tolerated. These takeoffs are simulated using a maximum gross weight of $2900 \mathrm{lb}$, standard day conditions, with 50 percent flaps, zero wind and a sea level field. All trajectories are required to have a climb speed of 84 knots. A takeoff at 2100rpm increases field length to the 50-foot runway obstacle by more than fifty percent. The initial climb rate measured at the runway obstacle falls from $927 \mathrm{ft} / \mathrm{min}$ to just $466 \mathrm{ft} / \mathrm{min}$. Altitude over the noise monitor drops to just $299 \mathrm{ft}$. To put it another way, altitude and climb rate are lost at a time when they are most welcome.

But in the case of a small electric airplane, it is possible that a manufacturer could list more than one engine takeoff "power" rating in its manual. Hypothetically, two takeoff power ratings could be defined for our electric SR20 variant. For a short field and best climb performance, the propeller would be set to 2700rpm for maximum thrust at low airspeeds. And a second takeoff power setting could be defined for a quiet takeoff at a lower propeller speed. Provided permission of regulating authorities is given, it is possible an applicant for a noise type certificate could have the choice of conducting noise certification tests using the low-noise mode promoted in this study. Regulatory precedent for this reasoning exists: the low-noise operating mode could qualify perhaps as a "selectable noise reduction system" under the provisions of [22]. Electric airplane reference trajectories are shown in Figure 7 (right). At a propeller speed of 2100rpm, for example, the takeoff field length grows by just 18 percent, and the initial climb rate falls from $927 \mathrm{ft} / \mathrm{min}$ to $784 \mathrm{ft} / \mathrm{min}$. A performance penalty of that order might be tolerable if a quiet takeoff is required.
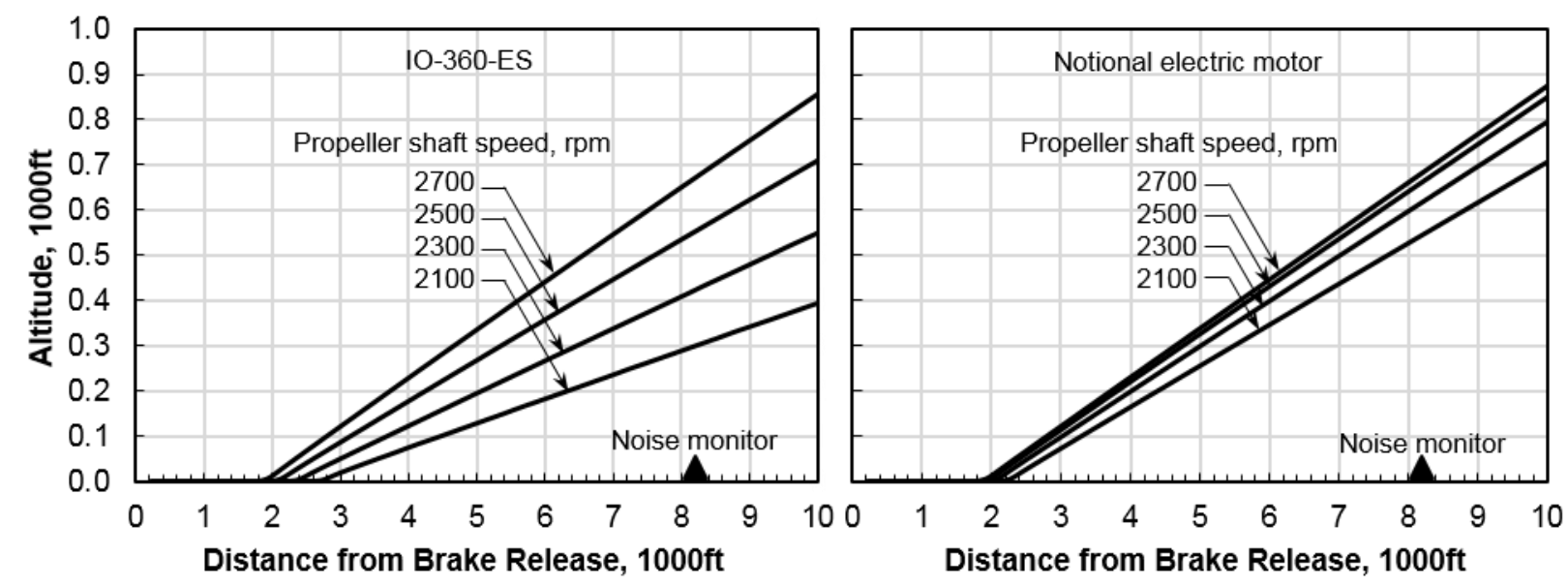

Figure 7. Takeoff reference trajectories; with IO-360-ES (left), vs. notional electric motor (right).

7 of 11

American Institute of Aeronautics and Astronautics 
For noise certification of new, propeller-driven light airplanes, the provisions of Chapter 10 of ICAO's Annex 16 [6] apply. In a noise test for airplanes of this type, the airplane is required to take off, climb, and fly directly over a noise observation monitor on the ground, located on the extended centerline of the runway $2500 \mathrm{~m}(8202 \mathrm{ft})$ from brake release. In an actual certification test, an equivalent test procedure is typically used that allows an applicant to avoid taking off and landing repeatedly for every noise measurement. Without actually taking off, a pilot will fly a course low over the ground that intercepts the reference climb path well before the noise monitoring station. After the interception point, the airplane follows the reference climb path. But equivalent procedures are designed to simplify the actual reference trajectory, while having no impact on noise at the monitoring station. Since the procedures are equivalent, the reference trajectories shown in Figure 7 are used directly in this study to analytically evaluate noise.

\section{B. Noise Levels}

1. Certification Noise

At the noise monitoring station, a single microphone is flush-mounted over an acoustically-hard surface at ground level. The ANOPP/PAS simulation used here analytically models this microphone. Like an actual certification test, predicted noise levels rise as the airplane approaches the noise monitor, and then fall as the airplane recedes. For these aircraft, regulation metrics are cast in terms of maximum A-weighted noise level, $L_{\text {Amax }}$. The peak A-weighted noise is taken as the Chapter 10 certification level.

The predicted certification noise of the stock SR20 equipped with the IO-360-ES engine and Hartzell propeller is $80.3 \mathrm{dBA}$. Referring to the SR20's type certificate [23], the published noise level is $82.6 \mathrm{dBA}$. The predicted level agrees well

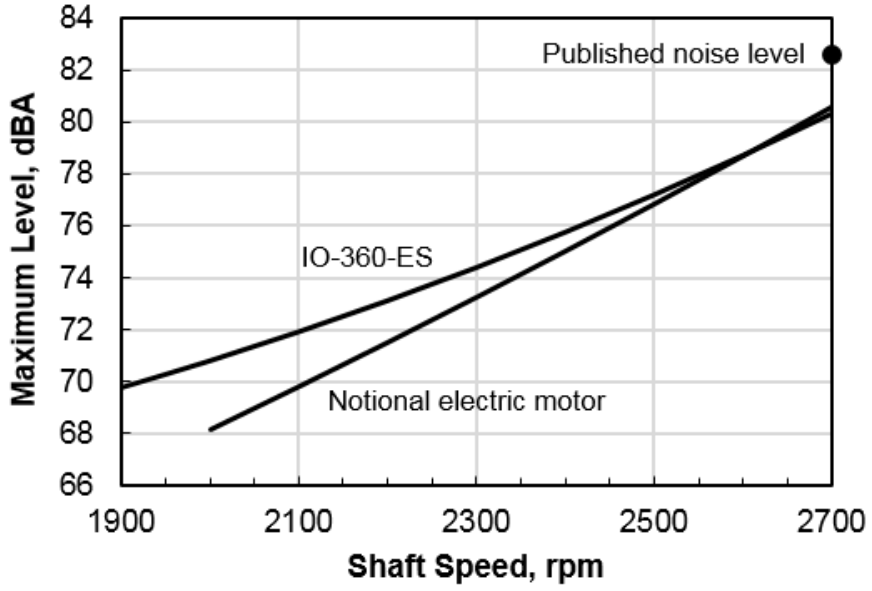

Figure 8. Influence of shaft speed on certification noise.

enough with the published level for the purposes of this study. The underprediction might be attributable to engine exhaust and propeller broadband noise content - neither of which are modeled in this study - as well as to the uncertainties in noise and trajectory modeling. Engine exhaust noise is deliberately omitted from this study, since this is a propeller noise investigation.

The influence of shaft speed on certification noise is shown in Figure 8. Additionally, shaft speed $N$, shaft power $P$, altitude over the noise monitor $h$, angle of attack $\alpha$, advance ratio $J$, blade pitch angle $\beta$ (as a fraction of a reference pitch angle), and $L_{\text {Amax }}$ are shown in Table 1. At 2700rpm, the noise of the electric variant is slightly higher than the stock SR20 because of the somewhat higher blade pitch angle and because its propeller is absorbing a bit more power. But noise is a strong function of propeller tip speed. As propeller speed is reduced, the levels of the stock SR20 and its electric variant fall. But owing to its higher flyover altitude, the electric variant is generally quieter at lower shaft speeds, despite the higher blade loading and noise associated with increased blade pitch angle.

Noise of the stock SR20 is predicted for shaft speeds as low as $1900 \mathrm{rpm}$. This is the lowest operational speed suggested for the IO-360-ES (though referring to Table 1, with a significant loss of power). Since all trajectories are required to have identical climb speeds, the differences in noise predictions due to airspeed, angle of attack and propeller inflow angle are small.

It should be noted that the noise levels predicted for the stock SR20 at low shaft speeds are purely hypothetical, since noise standards and reference procedures prohibit taking off with propeller speeds less than 2700rpm. But if "low-noise options" were documented in the airplane flight manual, an electric variant might be allowed to certify with a selectable range of shaft speeds. Noise of the electric variant is evaluated down to 2000rpm. Takeoffs at lower shaft speeds are not possible since the propeller blades begin to stall at the blade pitch angles necessary to absorb 200bhp. Results indicate that certification noise can be expected to fall by as much as $12 \mathrm{dBA}$ using the lowest shaft speed available, along with perhaps an acceptable field length and climb performance penalty.

8 of 11

American Institute of Aeronautics and Astronautics 
Table 1. Takeoff performance and propeller noise data at various shaft speeds.

\begin{tabular}{c|c|c|c|c|c|c|c}
\hline \hline Powerplant & $N, \mathrm{rpm}$ & $P, \mathrm{bhp}$ & $h, \mathrm{ft}$ & $\alpha, \mathrm{deg}$ & $J$ & $\beta$ & $L_{\text {Amax }}, \mathrm{dBA}$ \\
\hline \hline \multirow{5}{*}{ IO-360-ES } & 2700 & 196 & 671 & 2.64 & 0.52 & 0.323 & 80.3 \\
& 2600 & 187 & 614 & 2.65 & 0.54 & 0.338 & 78.7 \\
& 2500 & 177 & 552 & 2.66 & 0.56 & 0.353 & 77.2 \\
& 2400 & 168 & 489 & 2.67 & 0.58 & 0.369 & 75.8 \\
& 2300 & 158 & 423 & 2.68 & 0.61 & 0.385 & 74.4 \\
& 2200 & 148 & 361 & 2.69 & 0.63 & 0.403 & 73.1 \\
& 2100 & 138 & 299 & 2.70 & 0.66 & 0.421 & 71.9 \\
& 2000 & 130 & 244 & 2.71 & 0.70 & 0.443 & 70.8 \\
& 1900 & 121 & 192 & 2.72 & 0.73 & 0.467 & 69.8 \\
\hline \multirow{5}{*}{ Electric } & 2700 & & 682 & 2.63 & 0.52 & 0.327 & 80.6 \\
& 2600 & & 673 & 2.64 & 0.54 & 0.348 & 78.7 \\
& 2500 & & 661 & 2.64 & 0.56 & 0.372 & 76.8 \\
& 2400 & & 643 & 2.65 & 0.58 & 0.398 & 75.0 \\
& 2300 & 200 & 617 & 2.65 & 0.61 & 0.425 & 73.3 \\
& 2200 & & 588 & 2.66 & 0.63 & 0.454 & 71.5 \\
& 2100 & & 544 & 2.66 & 0.66 & 0.484 & 69.8 \\
\hline \hline
\end{tabular}

Table 2. Level, steady flight data at 150kts at various shaft speeds.

\begin{tabular}{c|c|c|c|c|c}
\hline \hline$h, \mathrm{ft}$ & $\alpha, \mathrm{deg}$ & $N, \mathrm{rpm}$ & $J$ & $\beta$ & $L_{\text {Amax }}, \mathrm{dBA}$ \\
\hline \hline \multirow{5}{*}{1000} & & 2500 & 0.99 & 0.445 & 74.0 \\
& & 2400 & 1.03 & 0.470 & 69.4 \\
& \multirow{3}{*}{0.58} & 2300 & 1.07 & 0.496 & 65.8 \\
& & 2200 & 1.12 & 0.525 & 62.9 \\
& & 2100 & 1.17 & 0.556 & 60.5 \\
& & 2000 & 1.23 & 0.591 & 59.3 \\
\hline \multirow{3}{*}{2000} & \multirow{3}{*}{0.67} & 2500 & 0.99 & 0.446 & 67.6 \\
& & 2400 & 1.03 & 0.470 & 63.1 \\
& & 2300 & 1.07 & 0.496 & 59.5 \\
& & 2200 & 1.12 & 0.525 & 56.7 \\
& & 2100 & 1.17 & 0.557 & 54.4 \\
& & 2000 & 1.23 & 0.592 & 53.2 \\
\hline \hline
\end{tabular}

\section{En Route Noise}

Low-noise, steady flight over areas requiring quiet operation are also of interest. The same low-noise operating mode used for takeoff noise certification could be helpful in reducing en route noise over residential areas or at night when demands for quiet are more common.

Using aerodynamics for the SR20 (now with flaps retracted) and knowing propeller characteristics, airplane performance for level, steady flight can be calculated (See Table 2). Shaft power is reduced and blade pitch is adjusted to create steady thrust at any given shaft speed and flight condition. In the case of the stock SR20, the propeller's hydraulic pitch-change mechanism, engine throttle, and fuel mixture would be adjusted to generate conditions for level, cruising flight. In the case of an electric airplane, the power conditioning equipment and electric pitch-change mechanism would be responsible.

Again, noise is seen to be a strong function of propeller tip speed. At 1000ft and 2000rpm, noise levels fall below $60 \mathrm{dBA}$ and the airplane stands an excellent chance of blending in with ambient noise. Incidentally, there are several advantages of full-authority digital engine control in a fully-electric general aviation airplane. Shaft speed could be optimized for best propeller efficiency (or for noise) for any given condition. The optimization could be extended to and combined with power efficiency information for the electric motor and power conditioning equipment to achieve optimum overall cruise efficiency. And in addition to efficient flight, such a system would relieve the pilot of monitoring cylinder head temperature, exhaust gas temperature, oil pressure and temperature, and engine speed. With adjustments to engine throttle and fuel mixture no longer necessary, pilot workload would be reduced.

9 of 11

American Institute of Aeronautics and Astronautics 


\section{Conclusions}

Low noise operation of a notional electric general aviation airplane has been studied. By exploiting shaft power characteristics of electric motors, a low-noise operating mode at reduced shaft speed can be enabled for variable-pitch propellers that are normally designed for performance rather than for noise. At reduced shaft speeds, high shaft power levels and high blade pitch angles could be combined to recover much of the thrust that would otherwise be lost. Low takeoff certification noise levels may be possible without the performance penalties ordinarily associated with reciprocating engines operating at reduced shaft speed. The low-noise operating mode could qualify perhaps as a selectable noise reduction system allowed by noise regulations. Analytical performance and noise comparisons are made for a stock Cirrus SR20 and an electric variant equipped with an equivalent electric motor. With perhaps an acceptable penalty in takeoff field distance and climb rate, results indicate propeller noise could be reduced by as much as $12 \mathrm{dBA}$ during takeoff.

\section{Acknowledgments}

Thanks to NASA's Transformational Tools and Technologies Project for supporting this study.

\section{References}

[1] Deere, K. A., et al., "Computational Analysis of a Wing Designed for the X-57 Distributed Electric Propulsion Aircraft," AIAA Paper 2017-3923, June 2017.

[2] Doyle, J., "Improvement in Motors for Propelling Vehicles or Mechanical Horses," U.S. Patent and Trademark Office, U.S. Patent 200,266 A, filed 4 Aug. 1877.

[3] Hartzell Propeller, Inc.: "2017 Price List” [online publication], URL: http://hartzellprop.com/wp-content/uploads/2017-PriceList-Orig.pdf, [retrieved Dec. 2017].

[4] Pankhurst, R. C., Conn, J. F. C., Fowler, R. G., and Love, E. M., "The Effect of Variation of Gear Ratio on the Performance of a Variable-pitch Airscrew for a High-speed Aeroplane," Reports and Memoranda No. 2039, Ministry of Aircraft Production, Aeronautical Research Committee, London, Oct. 1941.

[5] Gur, O., and Rosen, A., "Design of a Quiet Propeller for an Electric Mini Unmanned Air Vehicle," Journal of Propulsion and Power, Vol. 25, No. 3, May-June 2009, pp. 717-728.

[6] "Annex 16 to the Convention on International Civil Aviation, Vol. I: Aircraft Noise," International Standards and Recommended Practices - Environmental Protection, 7th ed., International Civil Aviation Organization, Montreal, July 2014.

[7] Berton, J. J., Freeh, J. E., and Wickenheiser, T. J., "An Analytical Performance Assessment of a Fuel Cell-Powered, Small Electric Airplane,” NASA TM-2003-212393, June 2003.

[8] “Cirrus SR20 Pilot's Operating Handbook and Airplane Flight Manual," Cirrus Design, P/N 11934-001, Reissue A, 1999.

[9] McDonald, R. A., "Modeling of Electric Motor Driven Variable Pitch Propellers for Conceptual Aircraft Design," AIAA Paper 2016-1025, Jan. 2016.

[10] “IO-360 Series Engine Maintenance and Operator's Manual,” Publication X30617, Continental Motors, Inc., Aug. 2011.

[11] Guynn, M. D., Berton, J. J., Haller, W. J., Hendricks, E. S., and Tong, M. D., "Performance and Environmental Assessment of an Advanced Aircraft with Open Rotor Propulsion," NASA TM-2012-217772, Oct. 2012.

[12] Gillian, R. E., “Aircraft Noise Prediction Program User's Manual,”NASA TM-84486, Jan. 1982.

[13] Zorumski, W. E., “Aircraft Noise Prediction Program Theoretical Manual, Parts 1 and 2,” NASA TM-83199, Feb. 1982.

[14] Nguyen, L. C., "The NASA Aircraft Noise Prediction Program Improved Propeller Analysis System,” NASA CR 4394, Sept. 1991.

[15] Nguyen, L. C., and Kelly, J. J., “A Users Guide for the NASA ANOPP Propeller Analysis System,” NASA CR 4768, Feb. 1997.

[16] Ffowcs Williams, J. E.., and Hawkings, D. L., "Sound Generation by Turbulence and Surfaces in Arbitrary Motion," Philosophical Transactions of the Royal Society of London, Series A, Vol. 264, No. 1151, 1969, pp. 321-342.

[17] Society of Automotive Engineers, "Standard Values of Atmospheric Absorption as a Function of Temperature and Humidity," Aerospace Recommended Practice 866A, 1975.

[18] Chien, C. F., and Soroka, W. W., "Sound Propagation Along an Impedance Plane," Journal of Sound and Vibration, Vol. 43, No. 1, Nov. 8, 1975, pp. 9-20.

[19] Society of Automotive Engineers, "Method for Predicting Lateral Attenuation of Airplane Noise," Aerospace Information Report 5662, April, 2006.

[20] McCullers, L. A., “Aircraft Configuration Optimization Including Optimized Flight Profiles,” NASA CP-2327, April 1984, pp. 396-412.

[21] Roskam, J., Airplane Design, Part VI: Preliminary Calculation of Aerodynamic, Thrust and Power Characteristics, $3^{\text {rd }}$ printing, Design, Analysis and Research Corporation, Lawrence, KS, 2000, Chaps. 4, 8.

10 of 11

American Institute of Aeronautics and Astronautics 
[22] "Environmental Technical Manual, Vol. I, Procedures for the Noise Certification of Aircraft," International Civil Aviation Organization (ICAO), Committee on Aviation Environmental Protection, $2^{\text {nd }}$ ed., Document 9501, 2015, pp. 3.47-3.48.

[23] European Aviation Safety Agency, "Type Certificate Data Sheet for Noise; No. EASA.IM.A.007 for SR20, SR22, SR22T," Entry C399, Issue 10, 15 Dec. 2017.

11 of 11

American Institute of Aeronautics and Astronautics 